\title{
CLIMATE CHANGE FOR AGRICULTURE, FOREST COVER AND 3D URBAN MODELS
}

\author{
M. Kapoor ${ }^{a *}$, D. Bassir ${ }^{b}$ \\ ${ }^{a}$ Computer Engineering Department, Mukesh Patel School of Technology Management and Engineering, NMIMS deemed to be \\ University, Mumbai, Maharashtra, India - er.muditkapoor@gmail.com \\ ${ }^{\mathrm{b}}$ Institute of Industry Technology, Guangzhou \& Chinese Academy of Sciences (IIT, GZ\&CAS) \\ Room A1005, R\&D Building, Haibin Rd, Nansha District, Guangzhou, China - david.bassir@ gziit.ac.cn \\ ${ }^{\mathrm{b}}$ Dept. GMC, Université de Technologie de Belfort-Montbéliard 90010 Belfort cedex France - david.bassir@utbm.fr
}

\section{Commission VI, WG VI/4}

KEY WORDS: Landsat TRIS/8/LDCM, Forest Change, Decision support, NDVI, Eclipse, 3D Urban Models

\begin{abstract}
:
This research demonstrates the important role of the remote sensing in finding out the different parameters behind the agricultural crop change, forest cover and urban 3D models. Standalone software is developed to view and analysis the different factors effecting the change in crop productions. Open-source libraries from the Open Source Geospatial Foundation have been used for the development of the shape-file viewer. Software can be used to get the attribute information, scale, zoom in/out and pan the shapefiles. Environmental changes due to pollution and population that are increasing the urbanisation and decreasing the forest cover on the earth. Satellite imagery such as Landsat 5(1984) to Landsat TRIS/8 (2014), Landsat Data Continuity Mission (LDCM) and NDVI are used to analyse the different parameters that are effecting the agricultural crop production change and forest change. It is advisable for the development of good quality of NDVI and forest cover maps to use data collected from the same processing methods for the complete region. Management practices have been developed from the analysed data for the betterment of the crop and saving the forest cover.
\end{abstract}

\section{INTRODUCTION}

The remote sensing technology now days become the boon for the different disasters, change detections like agricultural crop change, climate change and urbanisation in the form long and tall buildings. Crop rotation is the phenomenon of growing a number of different types of crop in the area of dissimilar periods in a year. Crop rotation gives different nutrients to the soil. A traditional element of crop is the increase of nitrogen through the use of green manure in sequence with cereals and other crops. Crop rotation also alleviates the build-p of pests that often occur when one species is continuously cropped, and can also improve soil structure and fertility by sporadic deep-rooted and shallowrooted plants.

Agriculture and fisheries are highly dependent on specific climate conditions. Trying to understand the overall effect of climate change on our food supply can be difficult. Increases in temperature and carbon dioxide $\left(\mathrm{CO}_{2}\right)$ can be beneficial for some crops in some places. But to realize these benefits, nutrient levels, soil moisture, water availability, and other conditions must also be met.

Changes in the frequency and severity of droughts and floods could pose challenges for farmers and ranchers. Meanwhile, warmer water temperatures are likely to cause the habitat ranges of many fish and shellfish species to shift, which could disrupt ecosystems.

Overall, climate change could make it more difficult to grow crops, raise animals, and catch fish in the same ways and same places as we have done in the past.

\footnotetext{
* Corresponding author
}

The effects of climate change also need to be considered along with other evolving factors that affect agricultural production, such as changes in farming practices and technology.

A series of satellite and airborne sensors have been developed to collect TIR data from the earth surface, such as HCMM, Landsat TM/ETM+, AVHRR, MODIS, ASTER, and TIMS. In addition to LST measurements, these TIR sensors may also be utilized to obtain emissivity data of different surfaces with varied resolutions and accuracies. LST and emissivity data are used in urban climate and environmental studies, mainly for analysing LST patterns and its relationship with surface characteristics, for assessing urban heat island (UHI), and for relating LSTs with surface energy fluxes in order to characterize landscape properties, patterns, and processes (Quattrochi and Luvall, 1999).

Landsat 8, a NASA and USGS collaboration, acquires global moderate-resolution measurements of the Earth's terrestrial and polar regions in the visible, near-infrared, short wave, and thermal infrared. Landsat 8 extends the remarkable 40 year Landsat record and has enhanced capabilities including new spectral bands in the blue and cirrus cloud-detection portion of the spectrum, two thermal bands, improved sensor signal-to-noise performance and associated improvements in radiometric resolution, and an improved duty cycle that allows collection of a significantly greater number of images per day. (D.P. Roy, 2014)

At over 40 years, the Landsat series of satellites provides the longest temporal record of space- based surface observations. Landsat 1 was launched in 1972 and was followed by a series of consecutive, temporally overlapping, Landsat observatories (Landsat 2, 3, 4, 5 and 7) that have provided near-global coverage reflective and thermal wavelength observations with increasing spectral and spatial fidelity (Lauer, Morain, \& Salomonson, 1997; Loveland \& Dwyer, 2012; Williams, Goward, \& Arvidson, 2006). 
Remarkably, the Landsat record is unbroken, with most land locations acquired at least once per year since 1972, capturing a period when the global human population has more than doubled (United Nations Population Division, 2011) and evidence for climate change has become discernible ( Hansen, Sato, \& Ruedy, 2012; IPCC, 2013). Landsat data offer a unique record of the land surface and its modification over time. The Landsat moderate spatial resolution is sufficiently resolved to enable chronicling of anthropogenic and natural change at local to global scale (Gutman et al., 2008; Townshend \& Justice, 1988)

\section{STUDY AREA}

Maharashtra is a state in the western region of India and is the nations and also the world's second-most populous subnational entity. It has over 110 million inhabitants and its capital, Mumbai, has a population of approximately 15.2 million. Mumbai is also the financial capital of the nation and the headquarters of all major banks, financial institutions and insurance companies in the country. India's Hindi film industry, Bollywood, and Marathi film and television industry are also located in this state. Maharashtra's business opportunities along with its potential to offer a higher standard of living attract migrants from all over India.

The Western Ghats is a mega-biodiversity region of the world. Twelve districts are covered in the Western Ghats region in Maharashtra.

In computer graphics, the surface of an irregular 3D object can be generally represented by a wire frame that consists of triangles or quadrilaterals as typical mesh elements. By successively simplifying the mesh elements, a coarser resolution of the wire frame can be derived. However, this approach is very inefficient, if not impossible at preserving the semantic and structural characteristics of building objects. In current 3D visualization systems, building objects are typically rendered at three pre-determined LoDs. During a fly-through, the three LoDs are dynamically switched over from one to another according to predefined distance thresholds. This is utilized to form the 3D building and models, so that we can access the urbanization in the Mumbai city. This is one of the parameter for the climate change.

Classification of agricultural lands as per its use for cultivation:-

$$
\begin{array}{ll}
1 & \text { Warkas land } \\
2 & \text { Jirayat land (Dry crop) } \\
3 & \text { Bagayat or irrigated land } \\
4 & \text { Rice land }
\end{array}
$$

1 The 'warkas' land is the land of the poor productivity. This land is used by the farmer during the monsoon to grow 'low-grade' millets such as nachani and warai. Its cultivation involved burning of the vegetation on the land, (rab manure) preparing the soil with a pick and sowing by hand.

2 Jirayat land is the land where cultivation is depends upon annual rainfall. The jirayat land is used for seasonal crops, kharif and rabi. The agricultural sessions of kharif crops starts from June and agricultural sessions of rabi crops are starts from September-October.

3 Bagayat or irrigated land:-.Cultivation of these lands is mainly dependent upon sources of water other than rain.
Sources of water can be well, bandharas and supply from Government's irrigation department.

4 Rice land:-In coastal and heavy rainfall area where main crop is rice, lands are classified into to two categories namely; rice land and warkas land.

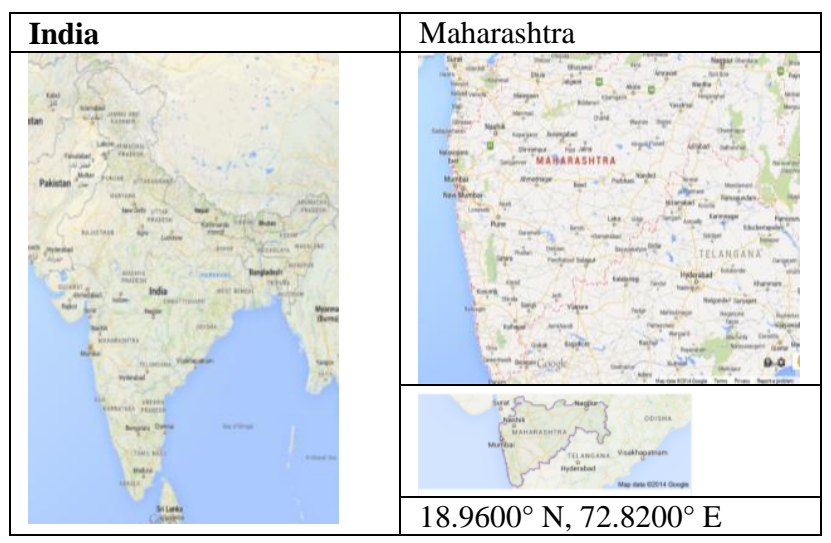

Table 1. Study area for the research

\section{METHODOLOGY}

Data of the Maharashtra has been for the various regions and contacted with farmers regarding the agricultural growth and production. So we found some of the yield related to their fields. Used this type of data and scaled to large areas. Software is developed to view the different scenarios and the shape-files of the regions. Eclipse is used to create the software. Other data processing software used like ArcGIS, Erdas Imagine and Q-GIS Desktop. Various 3D modeling softwares are used to create 3D buildings and analysis the different climate change scenarios.

Landsat TM FCC (bands 4, 3 and 2, scale 1: 50,000, October, 2009) were used for this study. The Landsat TM image was obtained in four separate images hence it was first mosaiced in Erdas Imagine software 10 before projecting it to UTM WGS 84 coordinate system. The study area was extracted by subsetting from the whole image. The flowchart of the methodology can be divided into five stages: (i) preparation of reference maps for gathering the existing and relevant information in the spatial form, (ii) pre-field classification of the satellite data, (iii) ground truthing, (iv) post-field correction and (v) field verification of the final map.

The maximum likelihood classifier calculates the probability that a pixel belongs to a class. Data from the training sets are assumed to be usually distributed, which allows the mean vector and the covariance matrix of the spectral cluster of each category of brightness values to be calculated (Lillesand and Kiefer, 2000). Supported on these results, the statistical probability of a pixel's brightness value consisting to each category of land use/cover can be calculated. The pixel is allotted to the category with the highest probability value. This classifier generally assumes equal probability of happening of each category of land use/cover. If experienced, one can define the probability of occurrence of each land-use/cover category before executing the image classification (known as a priori maximum likelihood classification). The necessary field corrections of the classified map were made and final vegetation map was prepared. The flow chart of the research methodology is shown in Figure 1. 


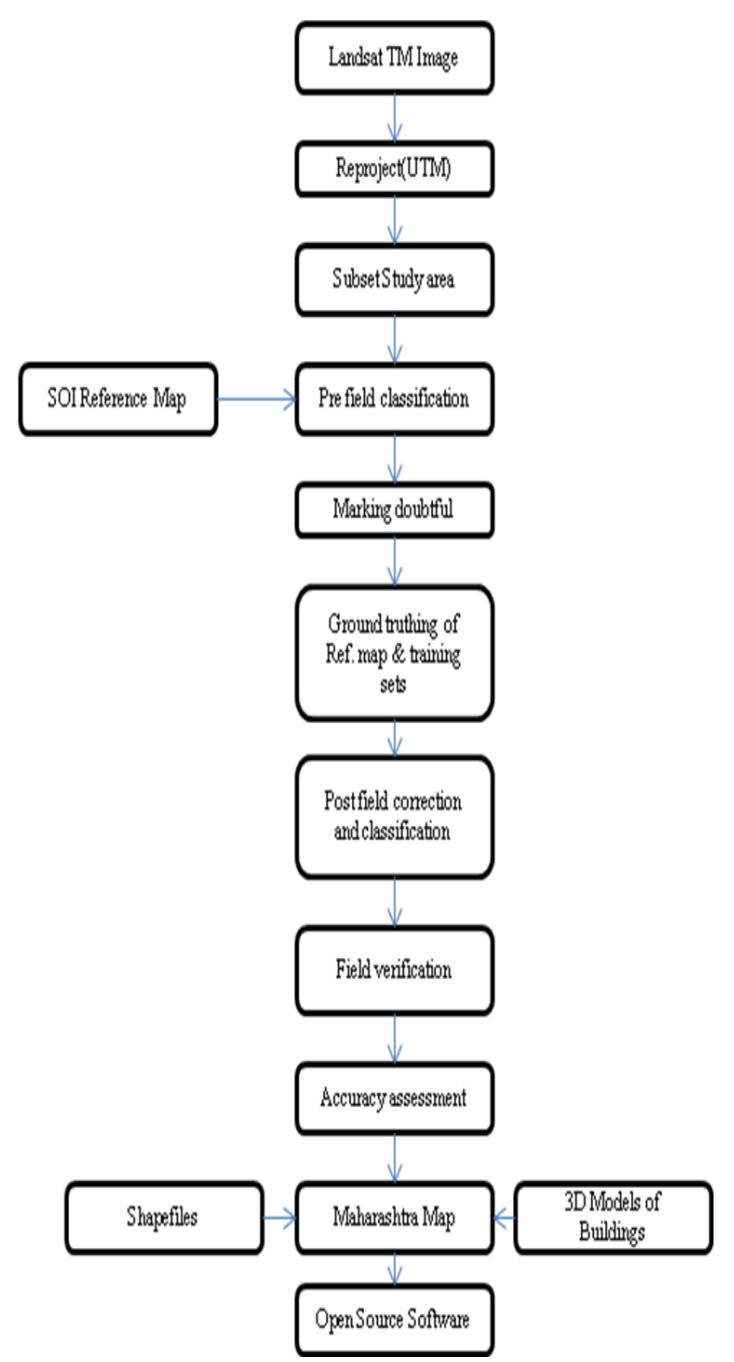

Figure 1. Methodology flow chart

\section{RESULTS}

The rectified LANDSAT TM scenes covering districts were analyzed to generate the vegetation map. All the major forest classes (viz. moist deciduous, semi evergreen, evergreen, dry deciduous, scrub forest and mangroves) were classified. Along withforest, other land use/cover classes (viz. agriculture, settlement, open land, fallow land and water bodies) found in the districts were also classified.

All the classification has been done on the satellite imagery in Erdas Imagine. Shapefiles of all the imagery are developed in the ArcGIS with all the attribute information so that can be used to draw meaning inferences and the yield and growth of the area.

The moist deciduous forests constitute the bulk of the total forest area and were found in all the districts of study area. Around 61 per cent of the forest area belongs to moist deciduous forests. Evergreen forest is covered by 2.10 per cent area while Semi evergreen and dry deciduous forest forms the remaining portion of the forest (Around 4.91 per cent under semi evergreen and 4.57 percent under dry deciduous forest). Agriculture constitutes 34.96 per cent of total area. The water bodies cover 2.63 per cent $(949.53 \mathrm{~km}$
2) area. Open land and scrub land covers an area of 29.47 per cent. The mangroves cover an area of 0.47 per cent and were found in the creeks of the districts of Landsat TM Image

Reproject (UTM) Subset Study area Pre field classification SOI Reference Map Ground truthing of Ref. map \& training sets Marking doubtful areas Post field correction \& classification Field verification Accuracy assessment.

The main tree species of this forest are Ain (Terminalia tomentosa), Jambha (Xylia dolabriformis), Kinjal (Terminalia paniculata), Sagwan (Tectona grandis), Surangi (Mammea suriga), Kokam (Garcinia indica), Kumbha (Careya arbprea), Karmal (Dillenia pentagyna), Amba (Mangifera Indica), Bibba (Semecarpus anacardium), Asana (Bridelia retusa), Anjani (Memocylon umbellatum ), Shisham (Dalbergia latifolia), and Khair

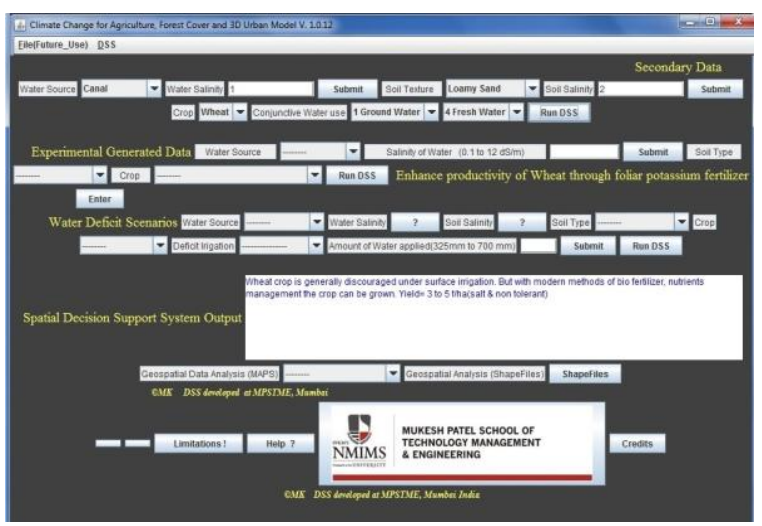

Figure 2. Software developed for the analysis

Software is developed is showing in the figure 2 with the following capabilities of Secondary data, experimental data and water deficit scenario, Geospatioal data analysis maps(shown in figure 3) and shape-file viewer in figure 3 with attribute information.

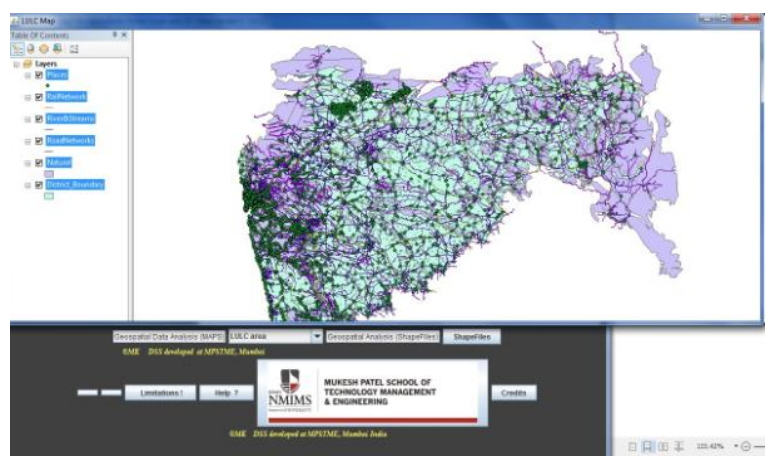

Figure 3. LULC map of the Maharashtra

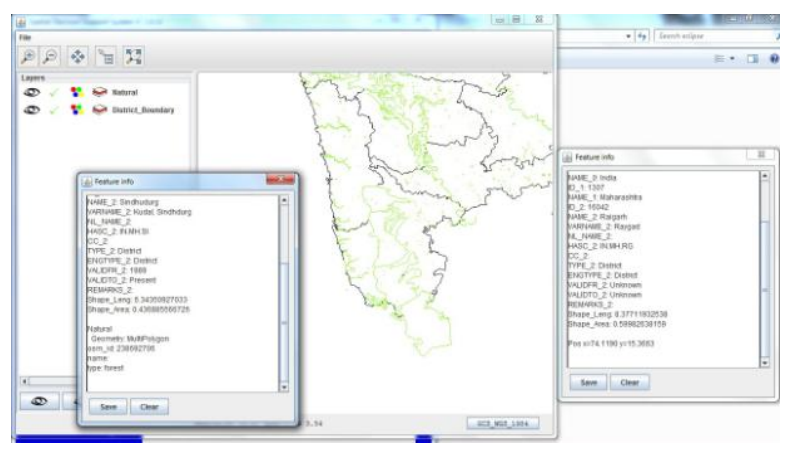

Figure 4. Shape-file viewer with attribute information 
3D Model information is shown over the google satellite imagery shown in figure 5. This is used to identify the prominent factors for the urbanization and climate change.

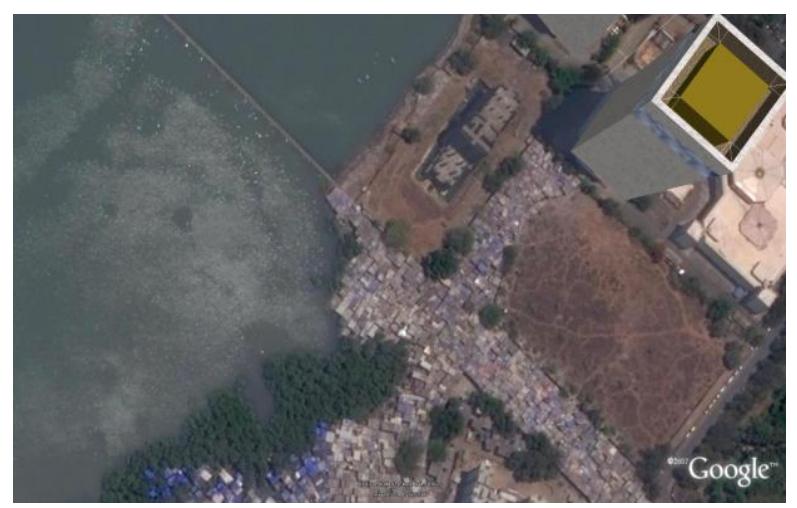

Figure 5. 3D Building showing over google map

\section{CONCLUSIONS}

The present study demonstrated effective role of the spatial technologies in mapping vegetation types. The results of vegetation mapping from remote sensing imagery represents well with actual vegetation community composition. The optimal use of satellite imagery in vegetation mapping is effective when it is complemented with fieldwork. When selecting a right vegetation classification system for better classification accuracy, the following points should be taken into consideration (i) refining class definitions to decrease ambiguity, (ii) adding sufficient number of new classes to describe the complexity of local vegetation patterns and (iii) using a higher level of classification.

It is preferable for production of good quality vegetation maps to use data acquired from the same sources and at the same period and applying the same processing methods for the entire region.

Various results have been verified with the agricultural production of the farmers of the Maharashtra and they are coming very close to the experimental values that have been provided in the software developed.

One interesting characteristic of mountains is that the climate changes rapidly with height over relatively short horizontal distances, and so does vegetation and hydrology. As a result, mountains exhibit high biodiversity, often with sharp transitions (ecotones) in vegetation sequences, and equally rapid changes from vegetation and soil to snow and ice. In addition, mountain ecosystems are often endemic, because many species remain isolated at high elevations, unlike lowland vegetation communities that can occupy climatic niches spread over wider latitudinal belts. In socioeconomic terms, mountain landscapes attract large numbers of people in search of opportunities for recreation and tourism.

Landsat 8 is equipped with LDCM which is push-broom sensor (Thermal Infrared Sensor) used for capturing the images of earth. It provides the wavelength for hotter and cooler object. Hotter objects can be identified with shorter wavelengths and cooler objects with longer wavelengths. This type of information is very much useful for the identification of the water requirements for crop production and climate change factors.

\section{REFERENCES}

Baccini, A., Friedl M. A., Woodcock, C E.,\&Warbington, R., (2004).Forest biomass estimation over regional scales using multisource data. Geophysical Research Letters, 31(10).

Buddenbaum, H., Schlerf, M., Hill, J., (2005). Classification of coniferous tree species and age classes using hyperspectral data and geostatistical methods. International Journal of Remote Sensing, 26(24):5453-5456.

Baret, F., \& Guyot, G., (1991). Potentials and limits of vegetation indices for LAI and APAR assessment. Remote Sensing of Environment, 35:161-173.

Chen, G., and Wang, J.W., (2008). Spectral reflectance and aboveground biomass estimation of the grassland under protection condition. Journal of Yunnan Agricultural University, 23:462-467.

Champion, H.G. \& S.K. Seth. (1968). A Revised Survey of the Forest Types of India. Govt. Of India Publications, New Delhi.

D.P. Roy, M.A. Wulder, (2014). Landsat-8: Science and product vision for terrestrial global change research. Remote Sensing of Environment, 145 pp.154-172

Gutman, G., Byrnes, R., Masek, J., Covington, S., Justice, C., Franks, S., \& Headley, R. (2008). Towards monitoring Land-cover and land-use changes at a global scale: The global land survey. Photogrammetric Engineering and Remote Sensing, 74, 6-10

Hansen, J., Sato, M., \& Ruedy, R. (2012). Perception of climate change. Proceedings of the National Academy of Sciences of the United States of America, 109,E2415-E2423.

IPCC (2013). Working Group I contribution to the IPCC Fifth Assessment Report Climate Change 20 13. The Physical Science Bas is, Final Draft Underlying Scientific-Technical Assessment (http://www.ipcc.ch/report/ar5/wg1/

Kapoor, M.; Khreim, J.F.; El Meouche, Rani E.M; Bassir, D.; Henry, A. L.; Ghosh, S. K. (2010) Comparison of Techniques for the 3D Modeling and Thermal Analysis. X Congreso Internacional Expresión Gráfica aplicada a la Edificación Graphic Expression applied to Building. International Conference in Alicante, Spain

Karnatak, H. C., Shukla, R., Sharma, V. K., Murthy, Y. V. S. and Bhanumurthy, V. (2012). Spatial mashup technology and real time data integration in geo-web application using open source GIS-a case study for disaster management. Geocarto International, 27(6), 499-514. doi:10.1080/10106049.2011. 650651

Quattrochi, D.A., Luvall, J.C., 1999. Thermal infrared remote sensing for analysis of landscape ecological processes: Methods and applications. Landscape Ecology 14(6), 577-598.

Lauer, D. T., Morain, S. A., \& Salomonson, V. V. (1997). The Landsat program: Its origins, evolution, and impacts. Photogrammetric Engineering and Remote Sensing, 63, $831-838$. Loveland, T. R., \& Dwyer, J. L. (2012). Landsat: Building a strong future. Remote Sensing of Environment, 122 ,22-29.

Torresan, S., Critto, A., Rizzi, J., Marcomini, A., (2012). Assessment of coastal vulnerability to climate change hazards at 
the regional scale: the case study of the North Adriatic Sea. Nat. Hazard. Earth Sys. 12, 2347e2368.

Townshend, J. R. G., \& Justice, C. O. (1988). Selecting the spatial-resolution of satellite sensors required for global monitoring of land transformations. International Journal of Remote Sensing, 9,187-236.

Tribbia, J., Moser, S.C., (2008). More than information: what California's coastal managers need to plan for climate change. Environ. Sci. Policy 11, 315e328.

UNEP/MAP, (2008). Protocol on Integrated Coastal Zone Management in the Mediterranean (Athens).

United Nations Population Division (2011). World population prospects: The 2010 revision. New York: United Nations (http://esa.un.org/unpd/wpp/index.htm).

Uran, O., Janssen, R., (2003). Why are spatial decision support systems not used Some experiences from the Netherlands. Computer Environment Urban 27, 511e526.

Verhoeven, G., 2001. Taking computer vision aloft Archaelogical three-dimensional reconstructions from aerial photographs with PhotoScan. Archaeological Prospection, 18, pp. 67-73.

Wackrow, R., Chandler, J. H., Bryan, P, 2007. Geometric consistency and stability of consumer-grade digital cameras for accurate spatial measurement. The Photogrammetric Record, 22(118), pp. 121-134.

Williams, D. L., Goward, S., \& Arvidson, T. (2006). Landsat: yesterday, today, and tomorrow. Photogrammetric Engineering \& Remote Sensing, 72 (10), 1171-1178. 